\title{
La integración de la gestión de la Atención Primaria de Salud y la Atención Hospitalaria
}

La integración de la gestión de la atención primaria de salud y la atención hospitalaria en una estructura directiva común ha sido y es motivo de debate. Distintas Comunidades Autónomas han optado por este sistema, originando publicaciones sobre sus ventajas e inconvenientes. La cuestión se ha planteado en diversos ámbitos profesionales con publicaciones monográficas de gestores interesados, con mucha frecuencia posicionados a favor del modelo en aras de la eficiencia. El planteamiento en los foros de atención primaria a menudo ha sido de prevención y en ocasiones de rechazo previo. El razonamiento básico es el temor manifestado a que los hospitales asuman un papel preponderante en la gestión integrada de las áreas de salud, sobre todo en cuestiones presupuestarias.

Creo que la postura frecuente de los profesionales de atención primaria (AP) de rechazo inicial a las reformas organizativas, por lo menos su escepticismo, debe ser rebatida por acciones que conviertan las amenazas en oportunidades. La presunción de pérdida en la fusión de gerencias ha de modificarse por una postura activa que persiga adecuar los perfiles competenciales de todos los profesionales. No es sólo en los juegos donde el apriorismo perdedor te sitúa de manera desfavorable.

La transferencia progresiva de competencias en asistencia sanitaria a las Comunidades Autónomas ha originado una progresiva implantación de los diferentes modelos de gestión. En la etapa final del Insalud sus directivos plantearon la necesidad de diseñar estructuras de área que unieran las gerencias existentes en una única gerencia que tuviera a su cargo toda la asistencia sanitaria de una determinada población. Ya entonces existían en las comunidades con competencias asistenciales estas direcciones, como en los distritos andaluces. La existencia de este proyecto condujo a la decisión de algunas de las autonomías que asumieron las transferencias en 2002 a adoptar el modelo de gerencia de área desde el inicio de sus competencias ese año.

En Castilla La Mancha se ha mantenido abierto el debate por la coexistencia del modelo clásico de gerencias de primaria y hospitales con la gestión integrada del área de Puertollano. Esta experiencia ha sido presentada por sus responsables en multitud de espacios de discusión, de gestión y profesionales, sometiendo sus prácticas a la comparación con otros modelos similares en España.
A mi juicio la debilidad fundamental de la discusión sobre diferentes formas de gestión es la dificultad de encontrar criterios de evaluación que permitan señalar sus ventajas e inconvenientes. Las opiniones sobre las fortalezas de cualquier sistema de gestión sanitaria a menudo son prejuicios basados en hipótesis no contrastadas. Las suposiciones más extendidas a favor y en contra de las virtudes de la gerencia de área pueden ser ocasionadas por el entusiasmo de sus defensores o la aversión al cambio de sus detractores.

La extensión de la gestión integrada a todo nuestro Servicio de Salud de manera progresiva se ha planteado con la llegada de un nuevo equipo directivo al Sescam. En todo caso se ha iniciado la planificación de un modelo de gestión de área sociosanitaria, con objetivo en el año 2020, que requiere necesariamente la integración de las estructuras de atención sanitaria, como previo a la integración con las instituciones de servicios sociales. La ambición del proyecto ha tenido la consecuencia de abrir la discusión en nuestro ámbito sobre las consecuencias en la atención primaria de esta previsión.

Es una opinión compartida por la gran mayoría de los profesionales que trabajamos en atención primaria la necesidad de reformas de gestión y de formas de trabajo. Esta necesidad ha sido recogida en los últimos años en documentos de las organizaciones profesionales y los servicios de salud, sobre todo en los acuerdos derivados de la AP XXI. En Castilla La Mancha se produjo con mucha rapidez la reforma de la AP en los años 80 , pero después no se han producido cambios fundamentales en los sistemas organizativos. El desarrollo estructural y de recursos que ha traído la competencia autonómica, que nos sitúa en primera fila entre los servicios de salud de España, no ha llevado aparejada la innovación en formas de gestión, repetidamente planteada y muy escasamente realizada.

Probablemente no es posible contrastar de manera experimental las mejores soluciones para la gestión de un área poblacional. Los buenos resultados de la gestión integrada se presentan muchas veces como efecto del modelo de gestión, pero no llevan la comparación con el control similar con otra forma de gestión. Por el contrario las opiniones en contra suelen ser efectivamente opiniones sobre supuestos agravios, casi siempre para atención primaria, rara vez evidenciados de manera explícita en su evaluación. 
En teoría al menos, es evidente la posibilidad de mejorar la eficiencia con gestión integrada, en particular en lo referente a los procesos de gestión administrativa y de compras. Es fácil prever que también puede mejorar la circulación de la documentación y los circuitos de comunicación. En palabras de un gerente de área, la mejor coordinación de decisiones es la que se hace con uno mismo, que decide unificar o simplificar los documentos y los trámites cuando tiene la responsabilidad de ambos ámbitos, primaria y hospital. Menos evidente es la relación de la calidad de la atención sanitaria en sentido estrictamente asistencial con los diferentes modelos de organización. De manera intuitiva, y así lo defienden los entusiastas de la gestión de área, es más fácil protocolizar procesos o delimitar responsabilidad cuando la decisión "obliga" a todos los implicados que cuando es necesaria la coordinación, que siempre supone voluntad explícita de acuerdo.

Los escépticos sobre las mejoras de la gestión integrada alegan la inequidad de las actuaciones de los responsables de área, que, impelidos por la potencia hospitalaria, tenderán siempre a minusvalorar la presupuestación de AP. Opinan que con instrucciones claras de quien debe hacerlo, las gerencias separadas estarían igualmente obligadas al acuerdo mediante la coordinación.

Procede en todo caso apelar al refranero español y no "poner la venda antes de la herida". Los supuestos perjuicios de la gestión integrada pueden responder a la presunción de que los gestores de área estarán inevitablemente secuestrados por los hospitales, como se dice que sucede con los pacientes.

La mejora de la capacidad resolutiva en atención primaria es una petición compartida por profesionales de atención primaria y quizás por los hospitales, incluso por la población, aunque de estas últimas intenciones tengo alguna duda. En mi opinión actual no veo mejor opción para esta mejora que decisio- nes "integradas", que no dejen a expensas de buenas intenciones el acceso a las pruebas diagnósticas, su correcto uso, la prescripción farmacéutica, o el alta de los procesos agudos, por ejemplo. La mejora de la calidad de la atención primaria actual en nuestro medio pasa, a mi juicio, por dos aspectos fundamentales: la mejora de la capacidad clínica, de diagnóstico y de tratamiento en atención primaria; y la real asunción de responsabilidad sobre sus actuaciones de los profesionales sanitarios. Para estos dos objetivos no encuentro dificultades en la gestión integrada de las áreas de salud, y creo que se presentan buenas oportunidades. La responsabilidad de los médicos y enfermeros, también de los gestores, que trabajamos en atención primaria es reivindicar y demostrar la capacidad resolutiva que reclamamos. Los ciudadanos deben conocer que en su centro de salud pueden y deben solucionar la inmensa mayoría de sus procesos, también con resultados en el tratamiento y control de la enfermedad, y no sólo valorar el papel de puerta de entrada y de confianza.

En todo caso recuerdo mi reflexión inicial de que la actitud de perdedor expresada al inicio de cualquier procedimiento innovador predispone necesariamente a ser tratado como tal. El impulso a las mejoras necesarias en nuestro trabajo deberá ser la consecuencia de una postura activa en las actuaciones, y no de la queja continua de quien a fuerza de solicitar no ser inferior puede llegar a creer serlo. La esperanza de que nuestras capacidades serán claramente conocidas y valoradas como merecen en una estructura integrada debe ser consecuencia de la decisión firme de adecuar nuestra capacidad clínica a la necesidad del paciente, que así lo reconocerá.

Rafael Muñoz Sánchez-Villacañas Médico de Familia

Director Gerente de Atención Primaria de Albacete 